\title{
nombalina
}

(8)

\section{Vulnerabilidade urbana a deslizamentos de terra em São Paulo}

$\begin{array}{ll}\text { Autor(es): } & \begin{array}{l}\text { Perez, Letícia Palazzi; Martins, José Rodolfo Scarati; Lombardo, Magda } \\ \text { Adelaide }\end{array} \\ \text { Publicado por: } & \begin{array}{l}\text { Imprensa da Universidade de Coimbra; RISCOS - Associação } \\ \text { Portuguesa de Riscos, Prevenção e Segurança }\end{array} \\ \text { URL } & \text { URI:http://hdl.handle.net/10316.2/34810 } \\ \text { persistente: } & \text { DOI:http://dx.doi.org/10.14195/978-989-96253-3-4_18 } \\ \text { DOI: } & \text { 26-Apr-2023 12:09:30 } \\ \text { Accessed : } & \end{array}$

A navegação consulta e descarregamento dos títulos inseridos nas Bibliotecas Digitais UC Digitalis, UC Pombalina e UC Impactum, pressupõem a aceitação plena e sem reservas dos Termos e Condições de Uso destas Bibliotecas Digitais, disponíveis em https://digitalis.uc.pt/pt-pt/termos.

Conforme exposto nos referidos Termos e Condições de Uso, o descarregamento de títulos de acesso restrito requer uma licença válida de autorização devendo o utilizador aceder ao(s) documento(s) a partir de um endereço de IP da instituição detentora da supramencionada licença.

Ao utilizador é apenas permitido o descarregamento para uso pessoal, pelo que o emprego do(s) título(s) descarregado(s) para outro fim, designadamente comercial, carece de autorização do respetivo autor ou editor da obra.

Na medida em que todas as obras da UC Digitalis se encontram protegidas pelo Código do Direito de Autor e Direitos Conexos e demais legislação aplicável, toda a cópia, parcial ou total, deste documento, nos casos em que é legalmente admitida, deverá conter ou fazer-se acompanhar por este aviso.

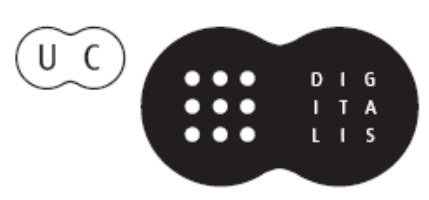



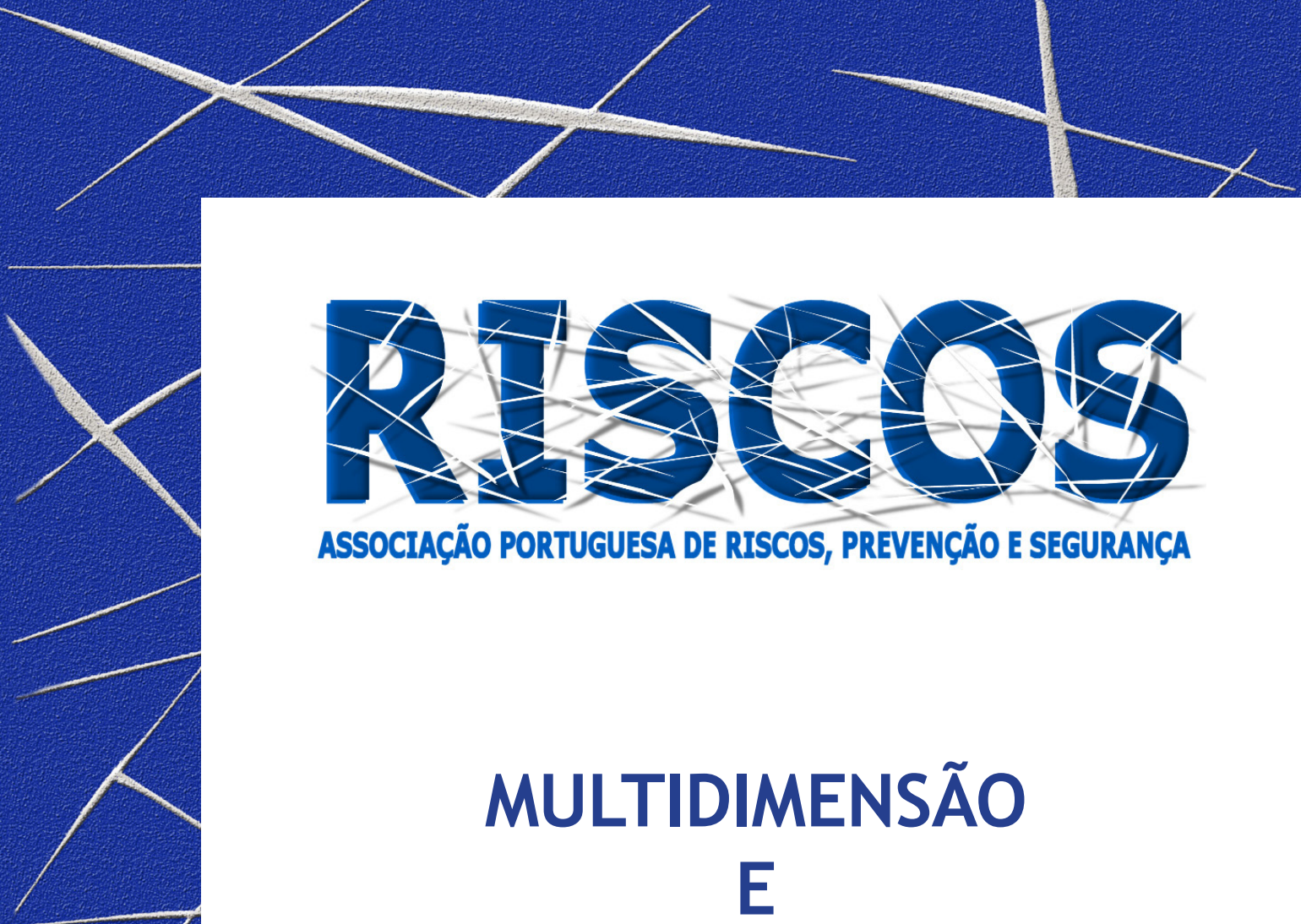

ASSOCIAÇÃO PORTUGUESA DE RISCOS, PREVENCCÃO E SEGURANÇA

MULTIDIMENSÃO

E
TERRITÓRIOS DE RISCO

III Congresso Internacional

I Simpósio Ibero-Americano

VIII Encontro Nacional de Riscos

Guimarães

2014 


\title{
VULNERABILIDADE URBANA A DESLIZAMENTOS DE TERRA EM SÃO PAULO
}

\author{
Letícia Palazzi Perez \\ Escola Politécnica da USP \\ leticia.palazzi@gmail.com leticia.palazzi@usp.br \\ José Rodolfo Scarati Martins \\ Escola Politécnica da USP \\ scarati@usp.br \\ Magda Adelaide Lombardo \\ Instituto de Geociências e Ciências Exatas, UNESP, Rio Claro, Brasil \\ lombardo@rc.unesp.br
}

\begin{abstract}
RESUMO
O município de São Paulo é o a maior do Brasil, possui $1.500 \mathrm{~km}^{2}$ de área, com praticamente $80 \%$ do solo impermeabilizado, e população de aproximadamente 12 milhões de habitantes (IBGE, 2011). A urbanização desordenada e a ocupação irregular de topos de morro e outras áreas de necessária preservação, tornam comuns as ocorrências de deslizamentos de terra, principalmente nas áreas mais carentes da cidade. Com base na análise de dados pluviométricos de 23 postos da rede telemétrica de pluviômetros de superfície do Departamento de Águas e Energia Elétrica, foram selecionados 7 eventos extremos de chuva em São Paulo. Para estas datas, foram coletadas as ocorrências de deslizamentos de terra.

Levando em consideração que deslizamentos de terra são eventos hidrológicos, relacionados à precipitação, e que a vulnerabilidade a deslizamentos pode ser georreferenciada, este trabalho apresenta o uso de ferramentas de engenharia e geotecnologias, para mensurar a vulnerabilidade urbana a deslizamentos de terra em São Paulo. Como resultado são apresentados mapas de vulnerabilidade urbana a deslizamentos, além da distribuição espacial destas ocorrências, associada a localização de habitação irregular, bem como a distribuição espacial da vulnerabilidade, associada ao Plano de HabitaçãoSocial de São Paulo.
\end{abstract}

Palavras-chave: vulnerabilidade urbana, geoprocessamento, deslizamento de terra.

Introdução

As notícias de deslizamentos de terra na cidade de São Paulo, Brasil, nos períodos mais chuvosos do ano, já são corriqueiras. Os deslizamentos de terra trazem risco de morte, além de prejuízos econômicos para a população e para o poder público.

Os anos de negligência do poder público ao planejamento de habitação de interesse social refletem, hoje, em um grande número de pessoas vivendo em áreas de risco ambiental, em várzeas, vertentes ou topos de morro, carentes de infraestrutura urbana.

As causas dos deslizamentos de terra são diversas desde ocupação de áreas de preservação, regularizadas ou não, habitações precárias e outros fatores como o aumento da impermeabilização acima do previsto.

A chuva é o principal condicionante dos deslizamentos de terra, objeto deste estudo, pois trata-se de movimentos de porções de um terreno, agravados pela presença de água.

Assim, tomando-se o registro de ocorrências de deslizamentos de terra mapeadas pela Defesa Civil da Prefeitura de São Paulo, para sete eventos extremos de precipitação, pode-se, a partir do georrefenciamento semi-automático (Perez, 2013), desenvolver uma analise espacial destas ocorrências em concomitância com o registro dos eventos pluviométricos, com o intuito de compreender sua relação com a frequência destes eventos. 
O objetivo deste trabalho é gerar um índice para mensurar a vulnerabilidade urbana de São Paulo a deslizamentos de terra, em função de eventos extremos de precipitação, com o apoio de geotecnologias, como subsídio à gestão urbana. Serão apresentados, como resultados, mapas de vulnerabilidade à ocorrência de deslizamentos de terra e sua relação com o mapeamento de assentamentos irregulares e o mapa de metas de intervenção da Secretaria de Habitação da Prefeitura de São Paulo, a fim de compreender como a distribuição espacial dos deslizamentos de terra está relacionada com o uso e ocupação do solo urbano.

\section{Materiais e métodos}

Para os sete eventos de precipitação selecionados, eventos extremos de chuva em São Paulo. São estes eventos: 23 maio de 2005, 07 fevereiro de 2007, 18 dezembro de 2007, 06 setembro de 2009, 07 dezembro de 2009, 20 janeiro de 2010 e 10 janeiro de 2011, foi calculada a média de precipitação por mesobacias hidrográfica em São Paulo, com base em matrizes de precipitação, criadas pela junção de informações do radar meteorológico de São Paulo e os dados da rede telemétrica de pluviômetros de superfície, do DAEE, com dados de precipitação a cada 10 minutos (Rocha, 2012), gentilmente cedidos pela FCTH. Com a precipitação média por bacia, foram calculados os períodos de retorno (TR) das chuvas, para 6, 12, 24 horas, para cada bacia, utilizandoas equações do DAEE (DAEE, 1999), e 48 horas, utilizando as equações do PDMAT 3 (DAEE, 2012), com o intuito de entender quais volumes de precipitação e consequentes TRs, seriam capazes de causar deslizamentos de terra.

De acordo com as correlações entre ocorrências de deslizamentos de terra e precipitação acumulada por pe'riodo de retorno, foi possível verificar grande correlação entre chuvas "comuns", ou seja, de curtos períodos de retorno, e as ocorrências. Assim, foram criadas classes de vulnerabilidade urbana das bacias para os TRs de 2, 5 e 10 anos, para cada período acumulado de chuva, de 6, 12, 24 e 48 horas, e as bacias foram classificadas, conforme Tabela I.

Tabela I - Classificação da vulnerabilidade a alagamentos.

\begin{tabular}{|l|l|}
\hline Ocorrências de Deslizamentos de Terra DC & Vulnerabilidade \\
\hline até 1 & baixa vulnerabilidade \\
\hline 1 a 6 & média vulnerabilidade \\
\hline 6 a 12 & alta vulnerabilidade \\
\hline mais de 12 & muito alta vulnerabilidade \\
\hline
\end{tabular}

Fonte: Elaborada por Perez, 2013.

\section{Resultados e discussão}

Um primeiro resultado mostra, conforme mapa 1, a distribuição espacial das ocorrências de deslizamento de terra e os polígonos de habitação irregular e/ou favelas em São Paulo. A análise espacial mostra que $48 \%$ das ocorrências de deslizamento de terra se deram a até 100 metros de assentamentos precários e $82 \%$ das ocorrências de deslizamento de terra se deram a até 300 metros de assentamentos precários mapeados pela Habitação.

O segundo resultado apresenta o mapeamento da vulnerabilidade urbana a deslizamentos de terra, em função da precipitação, por período de retorno e precipitação acumulada, conforme figura 1.

As bacias mais vulneráveis são aquelas com maior concentração de áreas de habitação irregular e/ou favelas. 

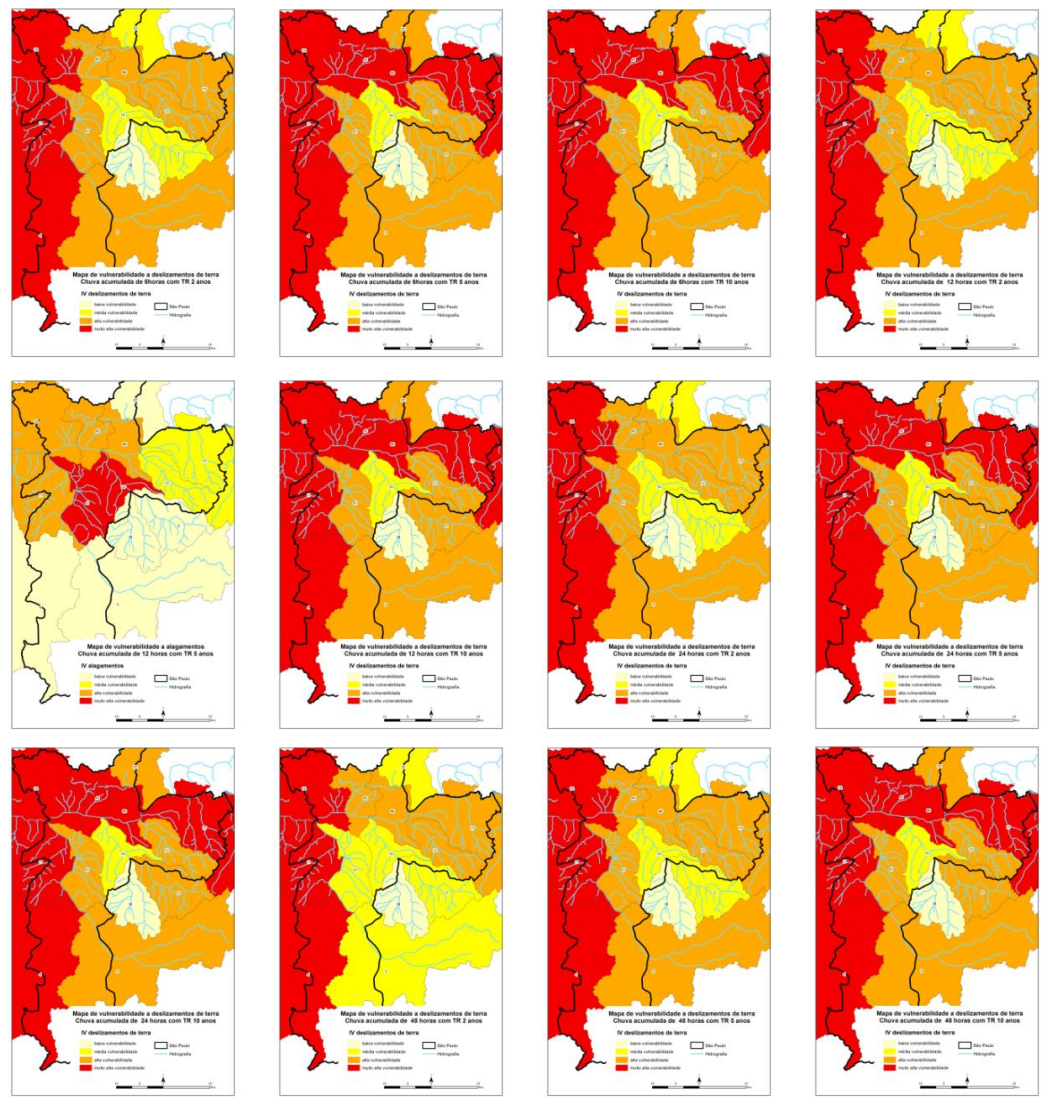

Figura 1 - Mapas de vulnerabilidade a deslizamentos de terra.
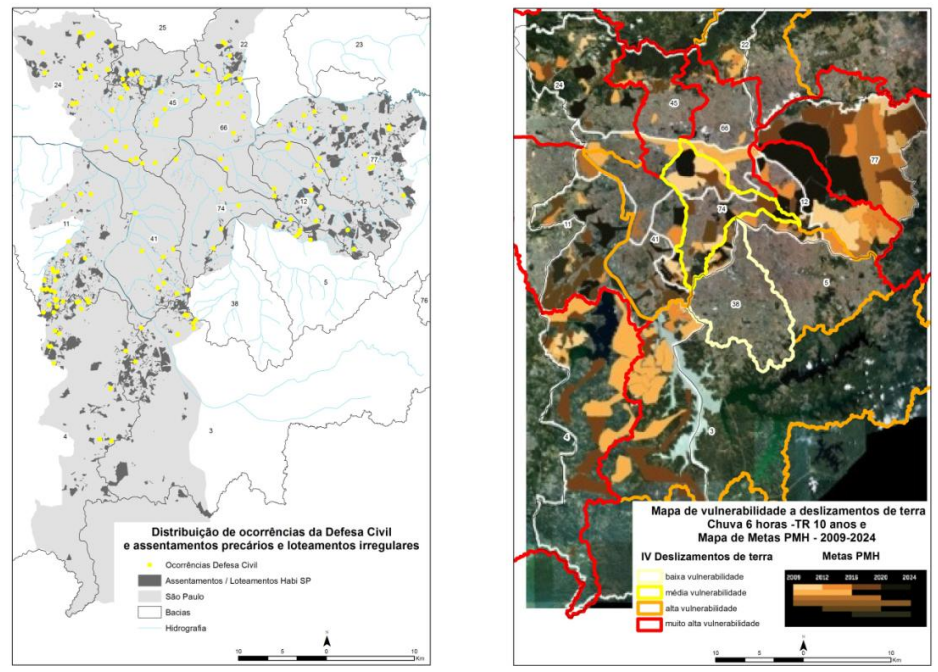

Mapa 1 e Mapa 2 
Por fim, o cruzamento do mapeamento da vulnerabilidade urbana a deslizamentos de terra com o mapeamento do Plano Municipal de Habitação (PMH) de São Paulo , mapa 2, mostra que as bacias mais vulneráveis são as mesmas com maior número de projetos de regularização e melhoria de infra estrutura urbana dentro do PMH.

\section{Conclusão}

O uso de tecnologia de última geração, como imagens geradas a partir de dados da rede telemétrica de pluviômetros de superfície e imagens de radar, técnicas de geoprocessamento, programação, e análises estatísticas permitiram construir um índice de vulnerabilidade urbana a eventos extremos de chuva, frente a ocorrência de deslizamentos de terra. Os mapas de vulnerabilidade das bacias, comprovam que foi possível a construção de um instrumento eficiente.

Este instrumento, que é o próprio índice de vulnerabilidade, permitiu a classificação das bacias por faixas de vulnerabilidade para a confecção dos mapas, sendo possível comprovar que os desastres estão relacionados à precipitação, e que os mesmos ocorrem, em áreas urbanas, por questões claras de conflito de uso do solo.

A falta de fiscalização por parte do poder público, em relação à ocupação irregular, bem como a permissiva especulação imobiliária são um problema a ser enfrentado.

\section{Bibliografia}

DAEE. Equações de chuvas intensas do Estado de São Paulo. Edição Revisada, São Paulo, Outubro de 1999. Convênio Departamento de Águas e Energia Elétrica e Escola Politécnica da Universidade de São Paulo.

DAEE. Relatórios do Plano Diretor de Macrodrenagem do Alto Tietê (PDMAT 3), São Paulo, 2012.

EMPLASA - Mapeamento GEGRAM. 1974.

HABI-SP - SECRETARIA DE HABITAÇÃO DA PREFEITURA DO MUNICÍPIO DE

SÃO PAULO. Plano Municipal de Habitação, PMH. Disponível em

$<$ www.habisp.inf. br> Acesso em agosto de 2013.

PEREZ, L.P. - Índice de vulnerabilidade urbana a alagamentos e deslizamentos de terra, em função de eventos extremos de clima, na Região Metropolitana de São Paulo: uma proposta de método. Tese de Doutorado. FFLCH - USP. São Paulo, 2013. PREFEITURA DO MUNICÍPIO DE SÃO PAULO - Dados Abertos. Acesso em maio/2014.

<http://www.prefeitura.sp.gov.br/cidade/secretarias/desenvolvimento_urbano/dados_abertos/> ROCHA FILHO, K.; CONDE, F.; ANDRIOLI, C.P. Correção em tempo real da precipitação estimada por um radar meteorológico com uma rede de superfície. XX SIMPÓSIO BRASILEIRO DE RECURSOS HÍDRICOS, Bento Gonçalves, Brasil. Nov 201 